EPJ Web of Conferences 106, 01002 (2016)

DOI: $10.1051 /$ epjconf/201610601002

(C) Owned by the authors, published by EDP Sciences, 2016

\title{
Dosimetry in Thermal Neutron Irradiation Facility at BMRR
}

\author{
J.-P. $\mathrm{Hu}^{1}$, N.E. Holden ${ }^{2}$, and R.N. Reciniello ${ }^{3}$ \\ ${ }^{1}$ NYS Professional Engineer, National Synchrotron Light Source II, Brookhaven Laboratory, \\ NY 11973, USA \\ ${ }^{2}$ Guest Physicist, National Nuclear Data Center, Brookhaven National Laboratory, Upton, \\ NY 11973, USA \\ ${ }^{3}$ Health Physicist (retired), Radiological Control Division, Brookhaven Laboratory, Upton, \\ NY 11973, USA
}

\begin{abstract}
Radiation dosimetry for Neutron Capture Therapy (NCT) has been performed since 1959 at Thermal Neutron Irradiation Facility (TNIF) of the three-megawatt lightwater cooled Brookhaven Medical Research Reactor (BMRR). In the early 1990s when more effective drug carriers were developed for NCT, in which the eye melanoma and brain tumors in rats were irradiated in situ, extensive clinical trials of small animals began using a focused thermal neutron beam. To improve the dosimetry at irradiation facility, a series of innovative designs and major modifications made to enhance the beam intensity and to ease the experimental sampling at BMRR were performed; including (1) in-core fuel addition to increase source strength and balance flux of neutrons towards two ports, (2) out of core moderator remodeling, done by replacing thicker $\mathrm{D}_{2} \mathrm{O}$ tanks at graphite-shutter interfacial areas, to expedite neutron thermalization, (3) beam shutter upgrade to reduce strayed neutrons and gamma dose, (4) beam collimator redesign to optimize the beam flux versus dose for animal treatment, (5) beam port shielding installation around the shutter opening area (lithium- 6 enriched polyester-resin in boxes, attached with polyethylene plates) to reduce prompt gamma and fast neutron doses, (6) sample holder repositioning to optimize angle versus distance for a single organ or whole body irradiation, and (7) holder wall buildup with neutron reflector materials to increase dose and dose rate from scattered thermal neutrons. During the facility upgrade, reactor dosimetry was conducted using thermoluminescent dosimeters TLD for gamma dose estimate, using ion chambers to confirm fast neutron and gamma dose rate, and by the activation of gold-foils with and without cadmium-covers, for fast and thermal neutron flux determination. Based on the combined effect from the size and depth of tumor cells and the location and geometry of dosimeters, the measured flux from cadmium-difference method was 4-7\% lower than the statistical mean derived from the Monte-Carlo modeling (5\% uncertainty). The dose rate measured by ion chambers was $6-10 \%$ lower than the output tallies (7\% uncertainty). The detailed dosimetry that was performed at the TNIF for the NCT will be described.
\end{abstract}

\section{Introduction}

Built in 1959 and continuously operated up to 1999, the 3 mega-watt power, light-water cooled Medical Research Reactor at the Brookhaven National Laboratory (BMRR [1]) was one of the earliest reactor facilities in the United States to treat patients and animals suffering from brain tumors and skin cancer,

This is an Open Access article distributed under the terms of the Creative Commons Attribution License 2.0, which permits unrestricted use, distribution, and reproduction in any medium, provided the original work is properly cited. 


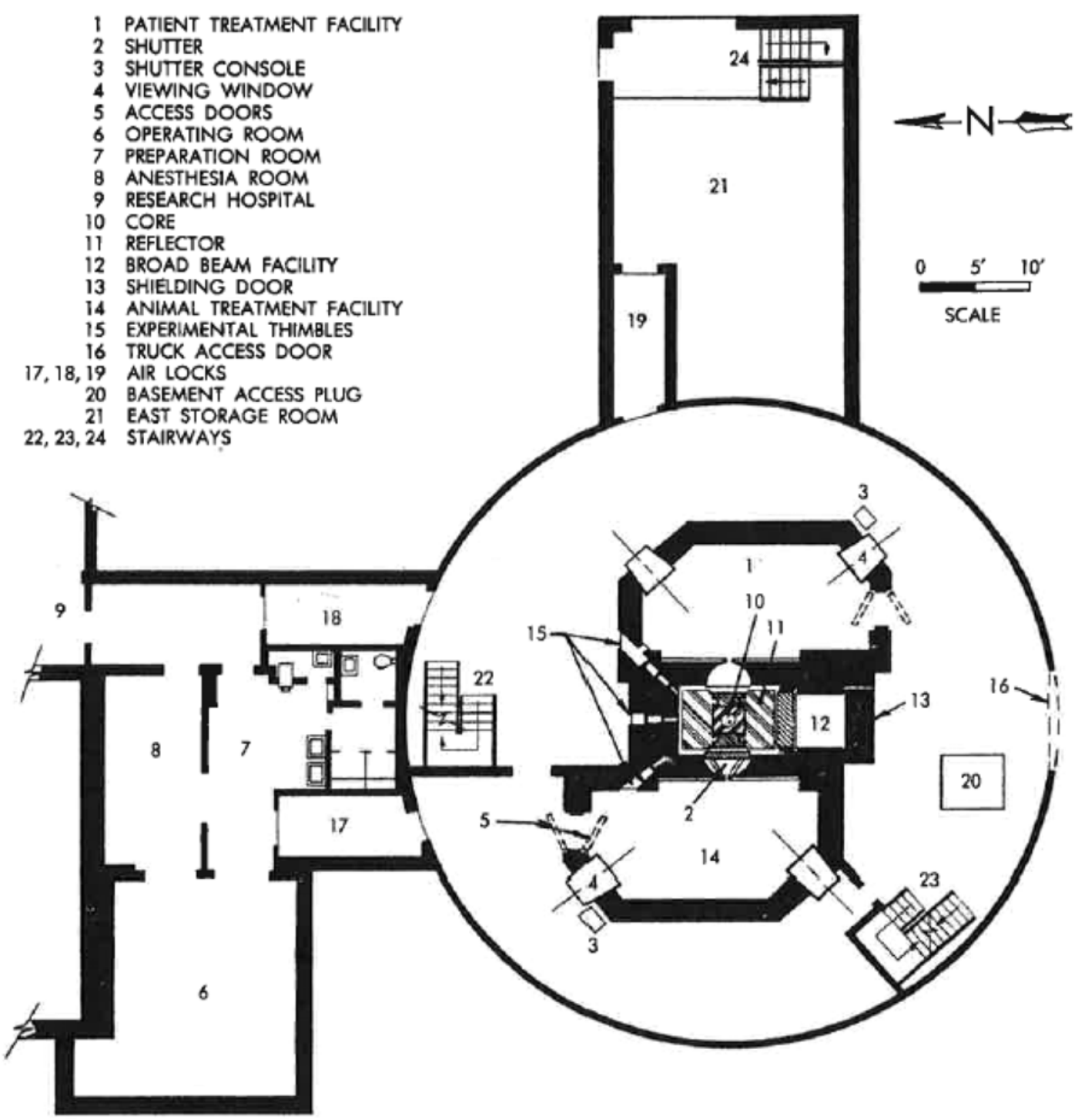

Figure 1. The BMRR consisting of a critical core (10), two symmetrically located treatment facilities $(1,14)$, a broad beam facility (12), 3 experimental thimbles (15), and a research hospital (9) for clinical trial of patients and small animals suffering from brain tumors or skin cancer.

using the epithermal and thermal neutron beams at, respectively, the patient treatment facility and animal treatment facility [2, 3], as shown in Fig. 1.

The thermal neutron beam which has a spectrum of energy at $<0.5 \mathrm{eV}$ was primarily generated for use in the clinical trial of Neutron Capture Therapy (NCT), a non-invasive therapeutic process for treating locally invasive malignant tumors [4]. The more penetrating epithermal neutron beam, which has a spectrum of higher energy between $0.5 \mathrm{eV}$ and $10 \mathrm{keV}$, was generated to treat deeply seated cancer cells, such as brain tumors within the cranium [5]. The tumor treatment on patients using the thermal neutron beam (1959-1994) then the epithermal neutron beam (1994-1999) at BMRR was a continuing effort of those made in 1954-1959 at Brookhaven Graphite Research Reactor [6], where a 
twenty-megawatt power, air-cooled and graphite-moderated neutron beam used for material irradiation and dosimetry studies had been modified to treat human subjects diagnosed as having malignant tumors [7].

The NCT is a two-step process; including the injection of tumor-localizing drug of high neutron absorption cross-section into the subject ( $1^{\text {st }}$ step), followed by a therapy during which the infused drug residing at tumor cells captures the penetrating neutrons and destroys the tumor in situ by exothermic reaction ( $2^{\text {nd }}$ step). When the thermal neutron beam was used in NCT to treat deeply-seated tumors, results from clinical trial were disappointing primarily due to the weak penetration of thermal neutrons. However, when treating subjects with tumors at shallow sites, such as eye melanoma and skin cancer [8], the NCT by thermal neutrons had notable success. This suggests the necessity of generating two neutron beams at different energy levels for cancer treatment.

In support of NCT, cell specimen tests and drug compound preparations were conducted in parallel by using other experimental facilities in the BMRR; including the three experimental thimbles which were built for fast sampling at core-edge high flux areas (accessible from exterior shielding wall), and the broad beam facility which was built for subject irradiation by a wide energy spectrum of neutrons and gammas. The pre- and post-treatment of patients and animals were performed in the research hospital, a full scale medical facility adjacent to the BMRR, established for lab employees' health and emergency services.

The modification and upgrade of the facilities at the BMRR had been done continuously to enhance the $\mathrm{R} \& \mathrm{D}$ clinical trials, where the major areas lay in the improvement of beam resolution (intensity, orientation, focusing), radiation dosimetry (dose, shielding) and subject handling (patients, animals). The NCT for tumor treatment on animals had been successfully continued at BMRR up to its decommissioning in 1999.

\section{Core Fuel Adjustment}

To sustain the operation of both thermal and epithermal neutron treatment facilities for clinical trials, installation of additional fuel elements at the critical core, to prepare for the needed flux tilt towards one of the two irradiation facilities, had become necessary. The flux tilt, which would induce core shift, was made to enhance the beam intensity for a more efficient treatment at beam port [9]. For demonstration, the horizontal midplane of a fully-loaded critical core, containing 31 fuel elements, 1 irradiation sample tube (A3) and 4 asymmetrically-located control rods (cadmium lined boron carbide $\mathrm{B}_{4} \mathrm{C}$ ), is shown in Fig. 2.

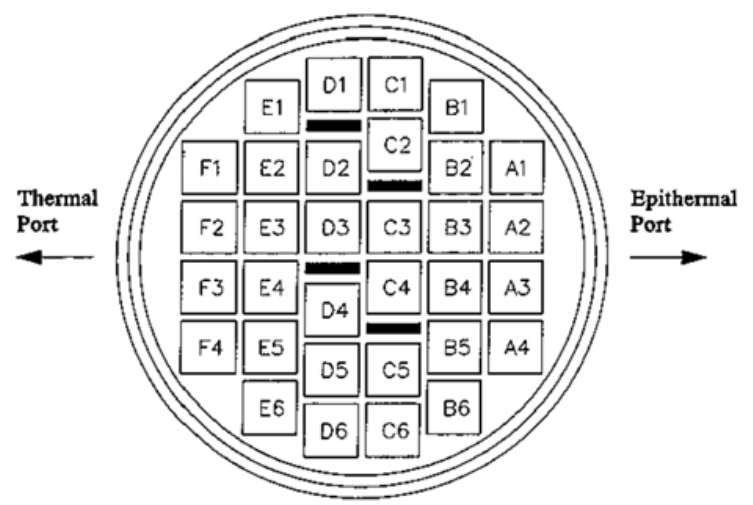

Figure 2. The critical BMRR core vessel (aluminum cylinder), consisting of 31 fuel elements (rows A to F), 4 control rods (black), 1 irradiation tube (A3) and multiple irregular graphite fillers, was an $\mathrm{H}_{2} \mathrm{O}$-cooled (through channels between fuel plates in element) and graphite-moderated critical assembly. 
Table 1. Neutron and gamma dose rate (per mega-watt) in the thermal treatment facility $( \pm 7 \%$ uncertainty).

\begin{tabular}{|l|c|c|}
\hline $\begin{array}{l}\text { Location in the Medical Reactor } \\
\text { Thermal Treatment Facility }\end{array}$ & $\begin{array}{c}\text { Measured vs. Calculated } \\
\text { Neutron Dose Rate }(\mathbf{m S v} / \mathbf{h})\end{array}$ & $\begin{array}{c}\text { Measured vs. Calculated } \\
\text { Gamma Dose Rate }(\mathbf{c G y} / \mathbf{h})\end{array}$ \\
\hline Facility side door, internal & 0.18 vs. 0.194 & 0.032 vs. 0.0298 \\
\hline Facility side door, external & 0.02 vs. 0.023 & ---- vs. 0.0017 \\
\hline Facility back wall, internal & 17.0 vs. 18.53 & 3.20 vs. 2.977 \\
\hline Facility back wall, external & 0.73 vs. 0.846 & 0.12 vs. 0.116 \\
\hline Viewing window, internal & 21.6 vs. 23.13 & 0.60 vs. 0.589 \\
\hline Viewing window, external & 0.02 vs. 0.023 & 0.02 vs. 0.018 \\
\hline Hutch back wall, internal & 737.0 vs. 778.6 & 48.0 vs. 44.88 \\
\hline Hutch back wall, external & 38.0 vs. 40.6 & 17.8 vs. 16.82 \\
\hline Collimator face & $100,000.0$ vs. $106,742.6$ & 667.0 vs. 627.6 \\
\hline Collimator face, $30 \mathrm{~cm}$ down, in axis & $20,000.0$ vs. $21,366.4$ & 133.0 vs. 124.3 \\
\hline
\end{tabular}

While A2 was a fresh type-B element (190 grams ${ }^{235} \mathrm{U}$ ) added to the core (in 1992), the A3 was an irradiation tube reserved for in-core fast sampling and vertical flux measurement. Radiation dosimetry and model calculations were performed at the completion of A2 insertion to compare with the early 30 -element core (4 type-B elements, 26 type-A elements with 140 grams ${ }^{235} \mathrm{U}$ each). Results indicate that the thermal neutron flux (Cd-difference method) and epithermal neutron flux (MCNP modeling [10]) at epithermal beam port (in patient treatment facility) were both increased by $\sim 6 \%$, and the thermal neutron flux at thermal beam port (in the animal treatment facility) was increased by $\sim 2 \%$, which partially compensated the flux loss from core shift but was deemed more than adequate for small animal and cell-culture irradiation [9]. The presence of A2 in the full 31-element core also increased the fast neutron and prompt gamma dose rate (ionization chamber), which was $4 \%$ and $1 \%$ at epithermal and thermal port, respectively. On average, the dosimetry measurement was $5 \%$ higher than the calculated values.

\section{Code Model and Dosimetry Measurement}

The model selected to simulate the full geometry of the BMRR critical core, core exterior graphite reflector, and inline material sections up to the sample holder reflector was the Monte-Carlo neutron and photon transport code, MCNP [10]. Both code run options, the criticality run ( $\left.\mathrm{k}_{\mathrm{eff}}\right)$ for the core multiplica-tion adjustment (plate-by-plate model) and the fixed-source run for a fast prediction of downstream fluxes and doses (homogenized core as a volumetric source), were chosen for tally processing to validate dosimetric data, which were obtained from the critical locations along the beam path, including the in-core irradiation tube (A3 in Fig. 2), core edge filler gaps, off-core graphite and bismuth slits, core-shutter interfacial spacing, beam port outer surface, ${ }^{6} \mathrm{Li}$-enriched polyethylene collimator exit, sample holder innards and holder reflector walls. Appropriate thermal neuron scattering functions $\mathrm{S}(\alpha, \beta)$ for $\mathrm{H}_{2} \mathrm{O}, \mathrm{D}_{2} \mathrm{O}$, graphite and polyethylene were employed in the computation. Continuous nuclear cross-section data libraries, ENDF/B-V, were adopted for the MCNP (version 4.2a) to calculate the flux and dose of neutrons ( $\pm 3 \%$ uncertainty), photons ( $\pm 5 \%$ uncertainty), and coupled neutrons-photons ( $\pm 7 \%$ uncertainty).

In regions outside of the critical core where the thermal neutrons and epithermal neutrons dominated, the selected method to measure the neutron flux was based on the use of bare and cadmium $(\mathrm{Cd})$ covered gold foils, since $\mathrm{Cd}$ has a large absorption cross section of thermal neutrons and gold has a known resonant energy $(4.9 \mathrm{eV})$ of epithermal neutrons. By subtracting the epithermal neutron activity at Cd-covered gold foil from the total activity at bare foil, the activation of thermal neutron alone was obtained; thereby the thermal neutron flux was calculated. The gold foils in use were $\sim 0.013 \mathrm{~mm}$ thick, with an average diameter of $7 \mathrm{~mm}$ and average mass of $9 \mathrm{mg}$. The cadmium cover used in the Cddifference method was $1 \mathrm{~mm}$ thick, deemed sufficient to block thermal neutrons. 


\section{$15^{\text {th }}$ ISRD}

The dose of gammas and fast neutrons in-air were measured by the thermoluminescent dosimeters TLD-600 and TLD-700, featuring neutron sensitive ${ }^{6} \mathrm{LiF}$ chip and standard ${ }^{7} \mathrm{LiF}$ chip respectively. By subtracting the neutron dose on TLD-600 from the total dose on TLD-700, the dose of gammas was calculated. The dose rate of fast neutrons was obtained from paired ionization chambers; one equipped with neutron-insensitive graphite wall and filled with $\mathrm{CO}_{2}$ gas for gamma estimate, and one filled with tissue-equivalent gas (i.e. $\mathrm{H} / \mathrm{C} / \mathrm{N} / \mathrm{O}=10.34 / 23.79 / 2.69 / 63.18$ in weight $\%$ [8]) for the mix-field total dose rate estimate [11]. The treatment room neutron dose rate (Table 1) was measured by an Eberline ASP1 Rem-Ball ${ }^{R}$, a real time neutron meter. The gamma dose rate was measured by the NRC ADM multi-purpose survey meter RadEye ${ }^{\mathrm{R}}$, capable of showing a linear dose rate crossing over 6 decades up to $1,000 \mathrm{cGy} / \mathrm{hr}$.

\section{Beam Shutter Upgrade}

The beam shutter located immediate upstream of the beam port in the treatment facility defined the beam for clinical trial when shutter was opened, and intercepted the beam for a safe shutdown when shutter was closed. With a weight of 21 tons, the hydraulically-elevated semicircular shutter consisting of an upper-half subassembly filled with neutron and gamma shield $\left(\mathrm{B}_{4} \mathrm{C}\right.$, steel, concrete) and a lowerhalf subassembly filled with neutron moderators $\left(\mathrm{D}_{2} \mathrm{O}\right.$, polyethylene liners) was confined in a vertical cavity. When the shutter was lowered, the upper half segment would "close" the window $(60 \mathrm{~cm}$ by $60 \mathrm{~cm}$ aperture) of core-to-port with shielding materials and so terminate the beam for clinical trial. When shutter was raised, the lower half segment would "open" the window of core-to-port for neutron beam to pass for NCT. To enhance beam intensity while reducing radiation dose, the shutter at thermal beam port had been modified.

\section{$\mathrm{D}_{2}$ O Tank Replacement}

Along the beam path towards the animal treatment facility, a $14 \mathrm{~cm}$ thick $\mathrm{D}_{2} \mathrm{O}$ tank followed by a $6.5 \mathrm{~cm}$ $\mathrm{D}_{2} \mathrm{O}$ tank at core-shutter interface, as shown in Fig. 3, were originally installed to efficiently therma-lize the core neutrons without parasitic capture. Separate filling of these two tanks, one at core side and the other one at shutter side, allowed the selection of different neutron energy [1]. Filling was done by pressuri-zing a reservoir in the BMRR basement, with $47 \mathrm{kPa}$ of helium. Individual plug valves were opened to fill each tank. The helium pressure was switched to the vent line for $\mathrm{D}_{2} \mathrm{O}$ draining when treatment is performed.
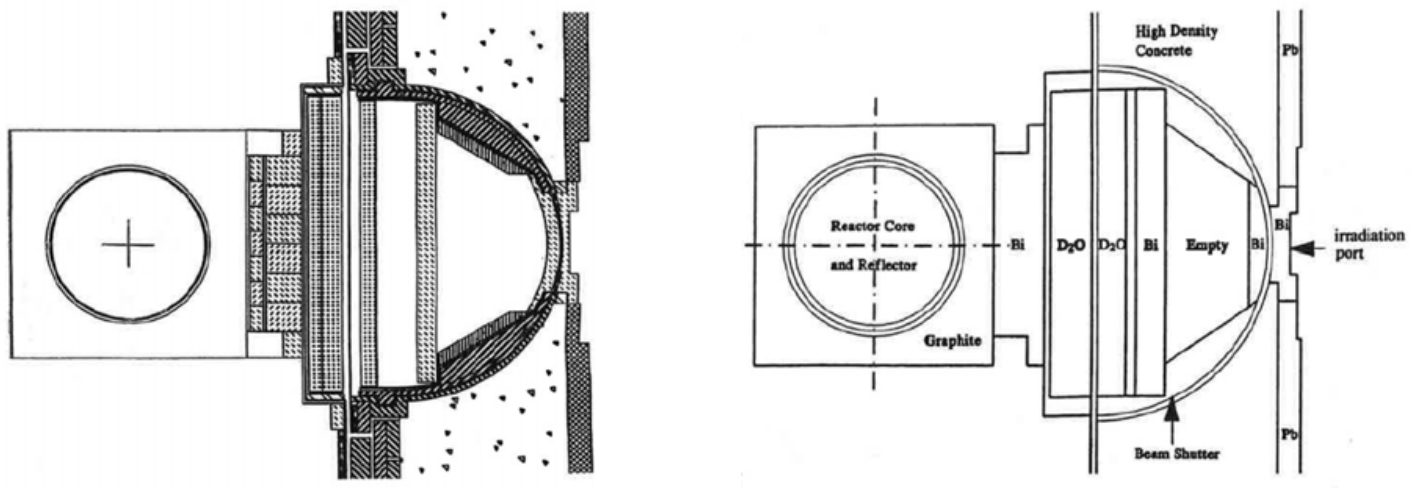

Figure 3. The thermal shutter in the right showed a modified version (1994) of that in the left (1961). 
To improve the thermal neutron flux while reducing the gamma dose at the beam port used for NCT, the semi-cylindrical thermal shutter (radius of $61 \mathrm{~cm}$ ) was modified to install a thicker $\mathrm{D}_{2} \mathrm{O}$ tank (from 6.5 to $10 \mathrm{~cm}$, in 2 air cooling gaps), a thicker bismuth gamma shield (from 6 to $10 \mathrm{~cm}$, followed by a shorter air-cooling gap from 43.5 to $33.4 \mathrm{~cm}$ ), and a thicker port shield (from $5 \mathrm{~cm}$ curved bismuth to a $7.6 \mathrm{~cm}$ straight one). During the NCT, both $\mathrm{D}_{2} \mathrm{O}$ tanks $(24 \mathrm{~cm}$, including walls) were fully filled.

\section{Side Liner and Port Shield Replacement}

Within the shutter and between the two bismuth shields at front and back, two $5 \mathrm{~cm}$ thick polyethylene liners backed up by steel fillers within the semicircular steel casing were installed to backscatter strayed neutrons (with a $30^{\circ}$ inward angle) and slowdown fast neutrons (using high H-content) in the central air cavity. During the port shield upgrade (bismuth, lead) in the early 1990s, the aged liners as shown in the left of Fig. 3 were replaced with longer pieces, extending to the shutter apex, to improve the beam intensity (higher thermal neutron flux) and focusing (smaller beam port aperture). To firmly hold the converging liners in symmetry, and to avoid radiation through the seams (line of sight), a thicker bismuth end-block $(7.6 \mathrm{~cm})$ was installed to replace the original curved one $(5 \mathrm{~cm})$. The bismuth port shield at downstream of the concave port face was also replaced, with a thicker block (from 2.5 to $7.6 \mathrm{~cm}$ ) to further reduce prompt gammas (by up to $45 \%$ ).

At completion of the upgrade, the neutron flux (Cd-difference method) and gamma dose (TLD) were measured to benchmark code outputs ( $<5 \%$ uncertainty). In a circle of $5 \mathrm{~cm}$ diameter, the measured thermal neutron flux per mega-watt was $(1.7 \pm 0.1) \times 10^{10} \mathrm{n} / \mathrm{cm}^{2}-\mathrm{sec}$, the fast neutron dose per thermal neutron per mega-watt was $(0.9 \pm 0.06) \times 10^{-11} \mathrm{cGy}-\mathrm{cm}^{2}$, and the prompt gamma dose per thermal neutron per mega-watt was $(2.7 \pm 0.1) \times 10^{-12} \mathrm{cGy}_{-} \mathrm{cm}^{2}[11]$. Both the flux and dose data are $\sim 4 \%$ lower than the code outputs.

\section{Collimator Optimization}

The installation of a portable collimator at the concave bismuth shield next to the shutter apex was aimed at enhancing the focusing of thermal beam for NCT while reducing the dose from a mixed field of neutrons and gammas over the wide surface of bismuth. As shown in the left of Fig. 4, the beam path of $1.7 \mathrm{~m}$ (67 inches) from the core center to the bismuth face had already dropped the thermal flux by two orders of magnitude, thus the collimator design became critical to meet the required focusing and shielding.
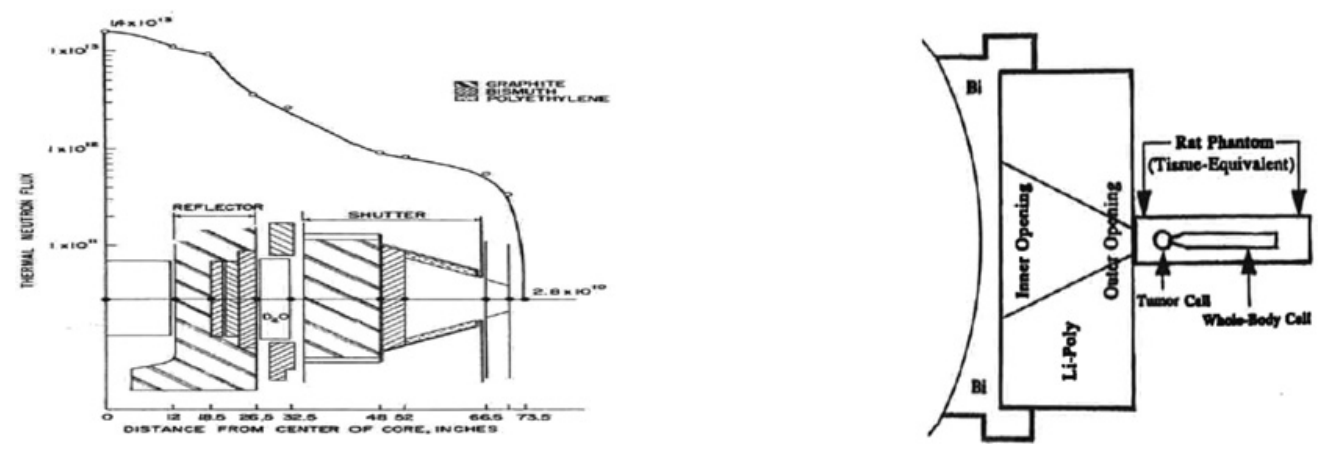

Figure 4. A plot of 3 mega-watt thermal flux from the BMRR core to the bismuth port in 1961 (left, horizontal midplane), and the $10 \mathrm{~cm}$ by $25 \mathrm{~cm}$ by $25 \mathrm{~cm}{ }^{6} \mathrm{Li}$-Poly collimator at bismuth port (right). 

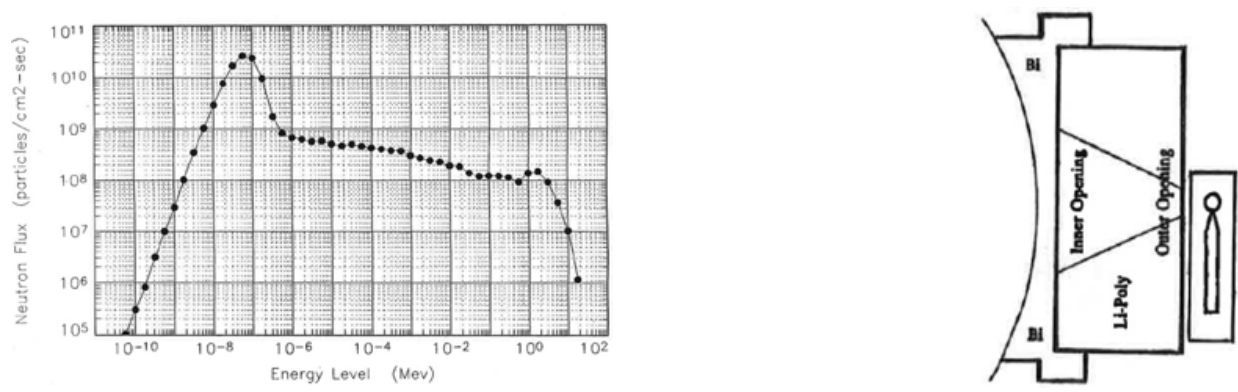

Figure 5. The left figure shows thermal neutron flux at bismuth face next to the shutter apex, and the right figure shows the position of sample holder which is in parallel with the collimator by keeping target at port.

Through model calculations based on different geometric configurations and material compositions, the optimum beam collimator was identified as a $10 \mathrm{~cm}$ thick, $25.4 \mathrm{~cm}$ wide and $25.4 \mathrm{~cm}$ high ${ }^{6} \mathrm{Li}$-enriched polyethylene $\left(\left[\mathrm{Li}_{2} \mathrm{CO}_{3}\right]_{2}\left[\mathrm{CH}_{2}\right]_{13}\right)_{\mathrm{n}}$ block, with an on-axis 12-to- $2 \mathrm{~cm}$ linearly-tapered aperture [8], as shown in the right of Fig. 4. Using bare and cadmium-covered gold foils in measurements for model validation, the flux of thermal neutrons at $12 \mathrm{~cm}$ opening facing the core was $(1.81 \pm 0.11) \times 10^{10} \mathrm{n} / \mathrm{cm}^{2}$-sec per mega-watt, and at $2 \mathrm{~cm}$ opening facing the NCT target was $(1.06 \pm 0.07) \times 10^{10} \mathrm{n} / \mathrm{cm}^{2}$-sec per mega-watt. Both were within $\pm 3 \%$ of the calculated flux. By the use of ionization chamber, the fast neutron dose rate obtained at $2 \mathrm{~cm}$ opening was $20 \pm 1.5 \mathrm{cGy} / \mathrm{min}$ per mega-watt, which was within $\pm 4 \%$ of the code output.

\section{Rebuilt Hutch at Thermal Beam Port}

Within the animal treatment facility as shown in Fig. 1, a shielding hutch was built in the 1970's at thermal beam port nearby to effectively confine the scattered neutron out of the collimator face. This $2 \mathrm{~m}$ deep by $2 \mathrm{~m}$ wide by $1.8 \mathrm{~m}$ high hutch which contained borax $\left(\mathrm{Na}_{2} \mathrm{~B}_{4} \mathrm{O}_{7} \cdot 10 \mathrm{H}_{2} \mathrm{O}\right)$ in its sidewalls for neutron capture, started leaking and caused contamination problems in 1990.

In 1992, a new hutch of $1.2 \mathrm{~m}$ deep by $1.2 \mathrm{~m}$ wide by $1.5 \mathrm{~m}$ high was proposed to replace the one that leaked. However, when the background radiation was identified to be exceedingly high due to denser scattering of neutrons in a smaller space, a larger hutch $(1.5 \mathrm{~m}$ by $1.5 \mathrm{~m}$ by $1.8 \mathrm{~m})$ built with 2 effective shielding layers $\left(5 \mathrm{~cm}\right.$ resin- $\mathrm{Li}_{2} \mathrm{CO}_{3}$ mixture with $93 \%$-enriched ${ }^{6} \mathrm{Li}$ in structural box, $10 \mathrm{~cm}$ polyethylene supporting plates) for neutron attenuation and ${ }^{1} \mathrm{H}$-induced gamma reduction was suggested [12]. Based on MCNP runs along with various measurements, including the use of activation foils, thermoluminescent dosimeters (TLD-600 and -700), real-time neutron meter (Rem-Ball ${ }^{\mathrm{R}}$ ), and multi-purpose gamma sensor $\left(\right.$ RadEye $\left.^{\mathrm{R}}\right)$, the suggested hutch was approved and built within the footprint of the dismantled one. Table 1 below lists the dose rate of neutrons and gammas measured and calculated at the new hutch and its surrounding areas up to the facility walls [13]. In general, the attenuation of both the neutrons and gammas was at least one order of magnitude, and in the case of the viewing window for neutrons, three orders of magnitude. In the case at the hutch wall, the attenuation for neutrons was a factor of 20 and for gammas 3 .

\section{Sample Holder Positioning}

When collimator was attached to the port, the beam intensity and focusing at its outer aperture became invariant. The remaining factor that could directly affect the resolution of NCT was the position of target under irradiation. The target referred to tumor cells in rat brain within an animal holder. Optimization of the holder position was performed based on a verified source plane (left of Fig. 5), 

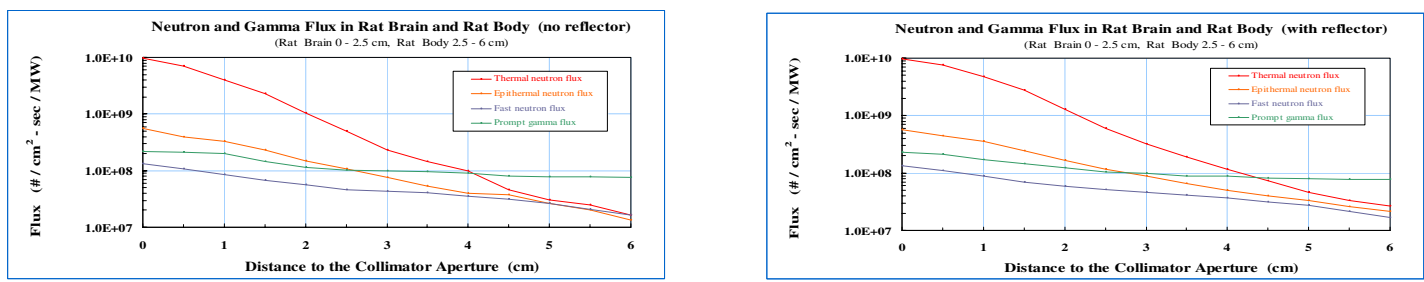

Figure 6. The left figure shows calculated neutron and gamma flux from the collimator face to the rat body. The right figure shows higher flux in rat due to backscattered neutrons from a $15 \mathrm{~cm}$ thick graphite block.
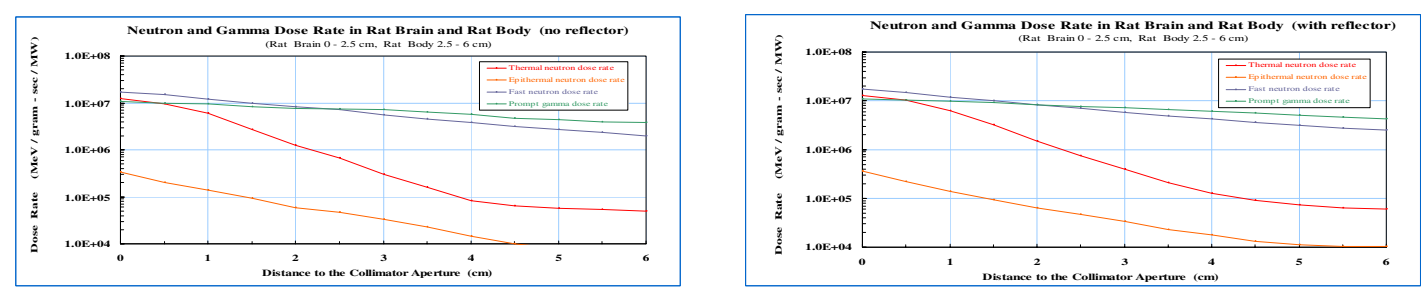

Figure 7. The calculated dose rate at rat brain and rat body in an on-axis holder in front of collimator port.

located at the bismuth face (also the collimator inner face) next to the shutter apex (right of Fig. 5). For sample holder that was positioned in parallel with the collimator surface (right of Fig. 5), the calculated thermal neutron flux at spherical brain cell filling with tissue-equivalent material (i.e. $\mathrm{H} / \mathrm{C} / \mathrm{N} / \mathrm{O}=10.34 / 23.79 / 2.69 / 63.18$ in weight percent, with physical density $1.04 \mathrm{~g} / \mathrm{cm}^{3}$ [8]) was $9.7 \times 10^{8} \mathrm{n} / \mathrm{cm}^{2}$-sec per mega-watt, and the average fast neutron and prompt gamma dose over the slender body cell were, respectively, $518 \mathrm{cGy}$ and $233 \mathrm{cGy}$ per mega-watt per hour. For sample holder that was positioned along the beam axis (right of Figure 4), the thermal neutron flux would drop $55 \%$ to $4.4 \times 10^{8} \mathrm{n} / \mathrm{cm}^{2}$-sec per mega-watt due to the presence of dense cranium (dominated by Ca, P) which shielded the brain cells, and the average whole-body fast neutron and prompt gamma dose would, respectively, drop $47 \%$ to 272 cGy and $39 \%$ to 143 cGy per mega-watt per hour due to body's self-shielding. For high resolution, the in-parallel position was adopted for the NCT.

\section{Sample Holder Reflector}

To enhance neutron flux and dose at target tumors, and to reduce stray neutrons and neutron-induced secondary gammas out of the collimator, a $15 \mathrm{~cm}$ thick by $25 \mathrm{~cm}$ wide by $25 \mathrm{~cm}$ deep graphite reflector block was placed next to the sample holder for the NCT since 1997. As shown in Fig. 6, the calculated flux of neutrons and gammas starting from the collimator outer aperture up to the rat brain $(0-2.5 \mathrm{~cm})$ and rat body $(2.5-6 \mathrm{~cm})$, with and without the presence of graphite, is displayed for comparison. Results indicate that the $15 \mathrm{~cm}$ graphite could effectively increase the thermal flux in rat (filled with tissueequivalent material) by $5 \%$ at brain and $11 \%$ at body, while reducing the background radiation.

The neutron and gamma dose rate was also calculated, based on the same model geometry for the flux estimate. As shown in Fig. 7, a higher dose rate was obtained from the presence of graphite reflector. It is noted that, due to a larger quality factor of energetic neutrons and large number of ${ }^{1} \mathrm{H}-$ induced gammas from neutron exposure, the dose rate in target cells is dominated by the fast neutrons and prompt gammas. 


\section{$15^{\text {th }}$ ISRD}

\section{Conclusion}

The major modification and upgrade of the thermal neutron irradiation facility at BMRR for NCT of small animals during 1959 and 1999 are presented. Through the improved thermal beam and experimental apparatus at the irradiation port, extensive clinical trials on rats and mice were able to be conducted especially in the 1990's when effective medical carriers and therapeutic protocols were developed for the brain tumor and skin cancer treatment. The outcome of NCT on small animals had vastly contributed to the similar non-invasive therapies performed on human subjects [14].

Through the in-core fuel arrangement, beam shutter upgrade, collimator redesign, sample holder repositioning and graphite reflector usage, a high-intensity high-quality and highly-focused thermal beam was produced, and the result was verified by the Monte-Carlo modeling and dosimetry measurements. While the gamma dose and dose rate were respectively measured by the TLD chips and ion chambers, the thermal and fast neutron dose was obtained from the product of quality factor and measured flux, using activated gold foils, with and without the cadmium cover. The measurements had been made along the beam path starting from the core edge bismuth blocks, through the semicircular shutter, up to the treatment room. As compared to the code output, the measured dose and dose rate is $\sim 3 \%$ and $5 \%$ lower, on average.

This research was supported by the US-DOE under the contract DE-AC02-98CH10886.

\section{References}

[1] J. Godel, Description of Facility and Mechanical Components, Medical Research Reactor (MRR), BNL 600 (T-173) (1960)

[2] R. Fairchild, Development and Dosimetry of an 'Epithermal' Neutron Beam for Possible Use in NCT-1, "Epithermal Neutron Beam Development", Phys. Med. Biol., Vol. 10(4), pp. 491-504 (1965)

[3] R. Fairchild, L. Goodman, Development and Dosimetry of an "Epithermal" Neutron Beam for Possible Use in NCT-1I, Phys. Med. Biol., Vol. 11(1), pp. 415-430 (1966)

[4] Surf http://en.wikipedia.org/wiki/File:NeutronCaptureTherapyImage.jpg

[5] S. Saraf, J. Kalef-Ezra, R. Faildchild, B. Laster, S. Fiarman, E. Ramsay, Epithermal Beam Development at the BMRR: Dosimetric Evaluation (ed. by O Harling, et al.), Plenum Press, pp. 307-316 (1990)

[6] Surf: http://www.bnl.gov/about/history/reactors.php \& http://energy.gov/em/ articles/brookhaven-lab-completes-decommissioning-graphite-researchreactor \& http://www.bnl.gov/bgrr/bgrr-complex.php

[7] L. Farr, W. Sweet, J. Robertson, C. Foster, H. Locksley, D. Sutherland, M. Mendelssohn, and E Stickley, NCT with Boron in Treatment of Glioblastoma Multiforme. Am. J. Roentgenol. 71:279-293(1954)

[8] H. Liu, J. Darrel, D. Slatkin, J. Coderre, Improved Apparatus for Neutron Capture Therapy of Rat Brain Tumors, Int. J. Rad. Oncol. Biol. Phys., Vol. 298(5), pp.1167-1173 (1994)

[9] H. Liu, R. Brugger, D. Greenberg, D. Rorer, J. Hu, H. Hauptman, Enhancement of Epithermal Neutron Beam used for BNCT, Int. J. Rad. Oncol. Biol. Phys., Vol. 28(5), pp. 1149-1156 (1994)

[10] J. Briesmeister (ed.), MCNP - A general Monte Carlo code for Neutron and Photon Transport, Los Alamos National Laboratory, LA-7396-M, Rev. 2 (1986)

[11] H. Liu, Design of Small-Animal Thermal Neutron Irradiation Facility at Brookhaven Medical Research Reactor, Nuclear Technology, Vol. 115, pp. 311-319 (1996)

[12] BMRR Treatment Room \#1 Beam Shield Change (Mod 90-3), an internal report of BMRR (1990) 
[13] N. Holden, J. Hu, D. Greenberg, R. Reciniello, Radiation Dosimetry for NCT Facilities at the BMRR, In: Hawthorne et al (ed) Frontiers in NCT, Kluwer Academic, Plenum Press (NY), pp. 587-591 (2001)

[14] J. Coderre, M. Makar, P. Micca, M. Nawrocky, H. Liu, D. Joel, D. Slatkin, H. Amols, Derivations of RBE for the High-LET Radiations produced during Boron Neutron Capture Irradiations of the $9 L$ Rat Gliosarcoma in vitro and in vivo, Int. J. Rad. Oncol. Biol. Phys. Vol. 27, pp.1121-1129 (1993) 